\title{
On the Way to Improve Diagnostic Marker Panel for Acute Appendicitis in Adults: the Role of Calprotectin
}

\author{
Adam Makaro $^{1}$ (D) $\cdot$ Łukasz Dziki $^{1}$ (D) Jakub Fichna ${ }^{2}$ (D) $\cdot$ Marcin Włodarczyk $^{1,2}$ (D)
}

Received: 11 April 2021 / Accepted: 28 July 2021 / Published online: 4 August 2021

(C) The Author(s) 2021

\begin{abstract}
Calprotectin is a positive acute-phase protein participating in innate immune responses and inflammatory processes. This protein is produced mainly in neutrophils, which infiltrate inflamed tissues and then increase the level of calprotectin in plasma, urine, or body secretions. Its measurement is used in the diagnosis of many inflammatory diseases of the gastrointestinal tract. Here, we reviewed the studies evaluating the utility of calprotectin when the patient is suspected of acute appendicitis, one of the most common causes of abdominal pain. Fecal and serum calprotectin provide clinicians additional information as compared to routinely performed laboratory analyses. Moreover, among all forms of the protein, the fecal calprotectin seems to be a particularly promising biomarker due to its high resistance to degradation in the stool. In the future, innovative methods in the form of neural networks may play a valuable role in developing such panels. These findings are important because current literature showed that sensitive and specific markers of acute appendicitis are still urgently needed.
\end{abstract}

Keywords Leukocyte L1 antigen complex · Appendicitis · Neutrophils · Acute-phase proteins · Feces · Abdominal pain · Immunity $\cdot$ Innate $\cdot$ Biomarkers

\section{Introduction}

Calprotectin (CP) is a small acidic protein belonging to the S100 family whose members comprise pseudo-EF-hands to coordinate $\mathrm{Ca} 2+$ ions. $\mathrm{CP}$ is a heterodimer consisting of MRP8/S100A8 and MRP14/S100A9 subunits containing iron, manganese, zinc, and calcium-binding sites [1]. $\mathrm{CP}$ is not only expressed mainly by neutrophils, but is also produced in monocytes and macrophages [2]. The metalbinding properties of CP lead to its antimicrobial functions in the nutritional immunity mechanism. The chelation of zinc and manganese reduces the microbial access to these valuable nutrient sources. On the other hand, recent observations provided novel insight into the microbicidal action of CP, which may be partly independent of metal bioavailability [3].

Marcin Włodarczyk

marcin.wlodarczyk@umed.lodz.pl

1 Department of General and Colorectal Surgery, Medical University of Lodz, Żeromskiego 113, 90-549 Lodz, Poland

2 Department of Biochemistry, Medical University of Lodz, Lodz, Poland
Extracellular CP plays a role in the innate immune system as one of the damage-associated molecular patterns (DAMPs), also called alarmins. These structures are recognized by receptors expressed on cells involved in nonspecific defense mechanisms, which initiate inflammation [4]. The role of $\mathrm{CP}$ in inflammation involves numerous mechanisms. It activates the NF- $\mathrm{KB}$ pathway, induces antinociceptive effect, inhibits immunoglobulin synthesis, and is a chemotactic factor for macrophages and neutrophils. What is more, the cell death-inducing activity of CP is also observed [5]. $\mathrm{CP}$ is one of the positive acute-phase proteins, so its concentration is increased in inflammatory sites. It is found not only within a cell but also in plasma, urine, and body secretions [6]. Upregulated CP appears in numerous pathological states, such as acute respiratory infections, rheumatoid arthritis, cystic fibrosis, multiple sclerosis, and inflammatory disorders affecting the gastrointestinal (GI) tract. The latter are characterized by an elevated level of CP especially in the stool. This fact becomes the subject of research on acute appendicitis (AA) diagnosis, in which CP may have a potential clinical application. 


\section{Increased Level of Fecal Calprotectin in Gastrointestinal Disorders}

During the inflammation of the intestinal tissue, the mucosal layer becomes more permeable. Moreover, when the intestine is infected, bacterial components act as stimuli for the release from immune cells. These reasons may contribute to the migration of neutrophils and the following secretion of $\mathrm{CP}$ into the fecal matter, which is then named fecal calprotectin (FC) [7]. It is highly resistant to degradation by bacteria and pancreatic or intestinal proteases. In addition, CP is stable for at least a week at room temperature and can be easily quantified by enzyme-linked immunosorbent assay (ELISA) [8]. Moreover, the main advantage of FC is direct contact with the mucosa that allows it to detect intestinal inflammatory conditions far more precisely than biomarkers measured in serum [9]. Taking it into consideration, $\mathrm{FC}$ is an excellent noninvasive biomarker of intestinal inflammation in some GI diseases. Among the disorders affecting the GI tract, inflammatory bowel diseases (IBD) are of particular importance in the context of the FC level. Two predominant types of IBD (Crohn's disease (CD) and ulcerative colitis (UC)) are characterized by chronic and relapsing intestinal inflammatory lessions [10]. The diagnosis of IBD involves biopsy and endoscopic examination; however, these procedures are unpleasant, have a risk of complications, and require a lot of commitment from medical staff. To limit the use of colonoscopy, non-invasive markers of intestinal inflammation were sought. One of them is FC with reliable clinical sensitivity and specificity [11]. The designation of its levels allows us to select patients who are more likely to need a colonoscopy and to distinguish IBD from functional diseases, such as irritable bowel syndrome (IBS). As a result of this approach, the number of colonoscopies performed in patients without IBD is minimized [12]. The percentage of false-negative FC is only about $6-8 \%$. Moreover, it was shown that FC is an excellent tool to estimate endoscopic activity of IBD [13]. Therefore, FC seems to be a reliable marker for predicting mucosal healing and, on the other side, for relapse of IBD [14, 15]. FC is also overactive during the course of other GI diseases. Its higher concentrations are found in samples of colorectal cancer (CRC) and adenomas. Currently, the measurement of FC may be used as a screening for CRC. Unfortunately, the results of updating meta-analysis from 2018 do not recommend the use of $\mathrm{FC}$ as a lone screening tool [16]. However, FC seems to have application in diagnosing and monitoring of diverticulitis and microscopic colitis (MC) [17]. These numerous clinical applications have led to further hypotheses linking the use of FC in inflammatory disorders of the GI tract. Currently, it is subject to considerable debate whether FC levels help diagnose the most common cause of abdominal surgical intervention, acute appendicitis (AA).

\section{Methods}

\section{Searching Strategy}

A systematic literature search was carried out to identify all original studies that analyzed the role of both fecal and serum calprotectin in management of adult patients with AA.

The systematic literature search involved the following databases: OVID MEDLINE and EMBASE. The search query consisted of the combination of the following keywords: "fecal calprotectin," "calprotectin," "MRP8/14," "S100A8/9," "acute appendicitis," "gastrointestinal." Results were limited to relevant papers published in English in 2012-2021. The first search was performed on 2 February 2020, and the search was updated on 11 October 2020, with a final revision on 9 November 2020.

\section{Study Selection and Risk of Bias}

The references in all the included studies were reviewed for more eligible articles. Each article was reviewed independently by three researchers (AM, JF, MW) for inclusion according to the inclusion and exclusion criteria, which follow. Disagreements regarding article selection were resolved through discussion until consensus was reached or resolved by discussion between authors LD and MW. Case series studies on accrual/historical adult patient records were included. Conference abstracts were excluded. Articles were also excluded if they were not in English, or the studies were preclinical research or commentaries. A standardized form was used to extract data from the included studies. Extracted details were study population and demographics, details of interventions and controls, study methodology, and information to assess bias. Data extraction was performed independently by four authors, and discrepancies were resolved through discussion with the other co-authors (Fig. 1).

\section{Outcome Assessment}

The main outcome was the accuracy of both fecal and serum calprotectin in management of AA adult patients. In addition, eligible pediatric studies were referred to in "Discussion." 


\section{Ethical Considerations}

Ethics committee approval was not required for this study because it was a systematic review. Patient consent was not required because no patients or patient-identifiable data were involved in the study.

\section{Results}

\section{Acute Appendicitis}

Acute appendicitis is one of the predominant indications for emergency surgery, with an estimated lifetime incidence of $7 \%$. Contrary to other etiologies of acute abdomen, AA occurs more commonly in children and young adults than in elderly patients [18]. Despite a high rate of incidence, the satisfying diagnostic approach has not been established yet. In AA, it is indispensable to have a diagnostic tool with high sensitivity to perform the surgical intervention early and then to prevent perforation. In addition, a high specificity is desirable to avoid unnecessary surgical intervention. To achieve this goal, clinical assessment, imaging strategies, and novel laboratory markers are used in daily clinical practice $[19,20]$. The group of biomarkers includes white blood cell count (WBC), granulocytes, c-reactive protein (CRP), the proportion of polymorphonuclear cells, and the level of CP [21]. CP is overproduced during the course of AA as a consequence of high neutrophil recruitment to damaged mucosa of the appendix and thus has gained much interest in AA diagnosis [22].

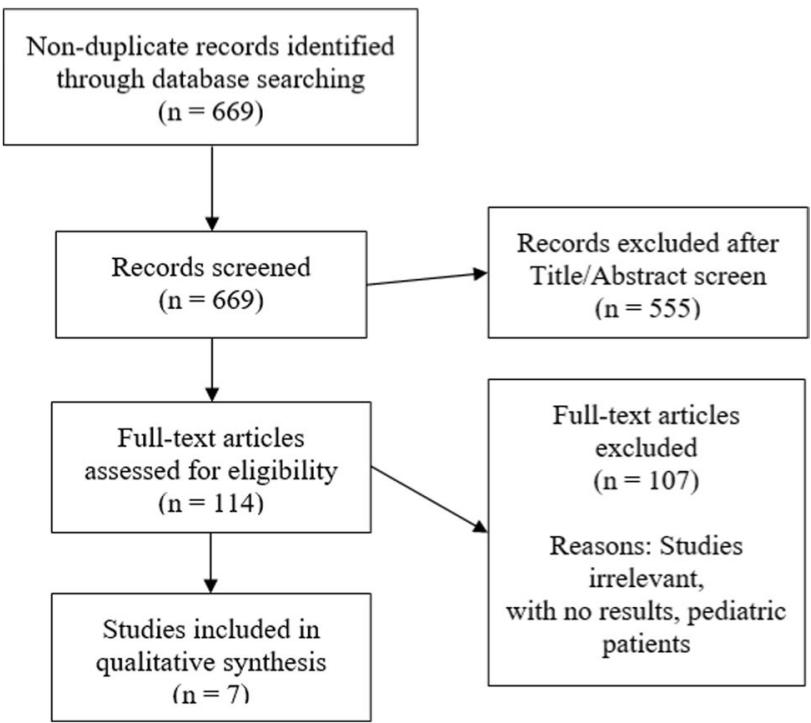

Fig. 1 PRISMA flowchart of the systematic literature search and selection process. PRISMA, Preferred Reporting Items for Systematic Reviews and Meta-analyses

\section{Serum Calprotectin}

What is worth noting is that the initial studies on the role of CP in AA were focused on the protein level in the serum (Fig. 2). They showed circulating form as a marker with high sensitivity but very low specificity rates $(16-53,6 \%)$ $[23,24]$. Most findings suggested its poor discrimination in the form of the low area under the curve (AUC) values in receiver operating characteristic (ROC) curve analysis. Nevertheless, the high sensitivity of CP could be helpful for clinicians to avoid surgical intervention in case of false-positive diagnosis. In addition, the level of serum CP may be able to bring more information than WBC and CRP used in routine clinical practice, which is not strongly correlated. The results of already published studies do not provide consistent data on the correlation between CP and other biomarkers [25, 26]. Handoffs note, the circulating protein in a single test is indicated as an excellent tool to identify complicated AA with necrosis or perforation, which requires clinical intervention [26].

\section{Fecal Calprotectin: Additional Opportunities?}

The hypothesis concerning FC as a tool for AA diagnosis was suggested in 2016 [27]. In the case series study, the post-appendectomy tissues were obtained from patients

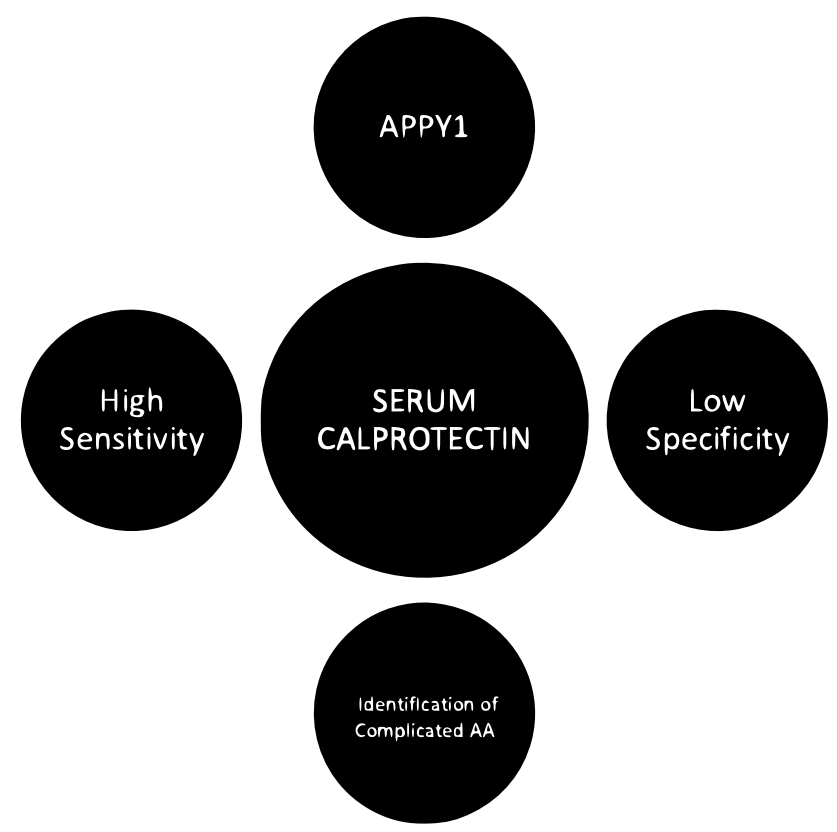

Fig. 2 A summary of information concerning the use of serum calprotectin (CP) in the diagnosis of acute appendicitis (AA). The biomarker provides high sensitivity but low specificity in adult screening. Considering pediatric studies, the APPY1 biomarker panel including serum $\mathrm{CP}$ is effective to identify the patients at low risk for AA. Moreover, it is helpful to distinguish complicated from uncomplicated AA in non-adults 
suspected of AA and then the expression of $\mathrm{CP}$ was measured by immunohistochemistry assay. The assessment of the immunostaining contained both epithelial and inflammatory cells of the vermiform appendix. These methods led to the finding that even if the appendicitis is uncomplicated, the immunochemical reaction with $\mathrm{CP}$ occurs. The main observation was the high overactivity of $\mathrm{CP}$ in the lumen of all inflamed samples which stays in contrast to the healthy appendix tissue. This may be the result of significant luminal infiltration of inflammatory cells.

The following pilot study tested the utility of FC as a marker of AA [28]. Stool samples were collected before the therapy and analyzed for FC concentration. The mean level of FC was higher in AA cases than that in controls (51.4 vs $24.8 \mu \mathrm{g} / \mathrm{g}$ ), but these results were not significant. The AUC was 0.869 with the cutoff value of $51 \mu \mathrm{g} / \mathrm{g}$, providing both sensitivity and specificity close to $80 \%$. Importantly, FC was effective to distinguish AA from infectious enteritis (IE), which is another most common cause of pain located in the right lower quadrant. The IE activity of the neutrophils is much more intense and the FC significantly $(p=0.007)$ exceeds the levels observed in AA, with the mean value of $320.9 \mu \mathrm{g} / \mathrm{g}$. A similar difference between IE and AA patients was not observed for routinely used WBC.

Recently, a study confirmed the significantly higher values of FC in the case of AA (240.5 vs $68.5 \mu \mathrm{g} / \mathrm{g}$ ) [29]. Noteworthy is the high AUC of 0.928 , which allows selecting the $106 \mu \mathrm{g} / \mathrm{g}$ cutoff point providing high sensitivity and specificity. Moreover, FC was significantly more active in complex (presence of a peri-appendicular abscess, gangrene, or perforation) than simple AA (206 vs. $304 \mu \mathrm{g} / \mathrm{g}$ ). The studies on the role of FC in the diagnosis of AA have been showed in Table 1.

\section{Discussion}

The diagnosis of AA is currently undergoing an intense debate. The commonly used scoring systems result in common misdiagnosis and overtreatment. As a result, too many patients underwent unnecessary surgery and then have been exposed to severe complications such as mechanical bowel obstruction, an incisional hernia, or infertility. This explains why searching for effective AA biomarkers is so important [31].

Recent observations suggest that $\mathrm{CP}$ is a potential marker for AA diagnosis. However, a small number of studies on adults is the limitation. For this reason, it is worthy to focus on pediatrics. Considering several studies, the serum $\mathrm{CP}$ may serve a role in biomarker panel APPY1 diagnosing AA. The APPY1 panel including serum CP, WBC, and CRP has a high negative predictive value and allows reducing computer tomography utilization in patients suspected of suffering from AA, which is particularly important in case of non-adults [32-35]. More recently, a research evaluated the accuracy of clinical manifestations, laboratory analyses, and imaging methods for the diagnosis of AA [36]. They found that each marker used individually does not provide satisfying power, and the classic physical examination is still the most important single tool. The study provided new perspectives on the use of serum CP in diagnostic panels. The multivariate analysis of all markers was performed using neural networks. This innovative approach showed that the combination of physical examinations, biomarkers, including serum $\mathrm{CP}$, and ultrasonography is a much more effective diagnostic panel than APPY1. This conclusion was in line with another study, in which a 6-part score including serum CP revealed great accuracy to predict appendicitis [37].

Another study offered new insight into CP utility due to the parallel measurement of the serum and fecal form in the

Table 1 The studies on the role of fecal calprotectin in the diagnosis of acute appendicitis

\begin{tabular}{|c|c|c|c|c|c|c|}
\hline & Patient group & Sensitivity (\%) & Specificity (\%) & Cutoff value & AUC & Comments \\
\hline $\begin{array}{l}\text { Ambe et al. [27] } \\
(2016)\end{array}$ & 52 & - & - & - & - & $\begin{array}{l}\text { 1. Study on predominantly adult population } \\
\text { 2. High accumulation of CP in the lumen of } \\
\text { an inflamed appendix }\end{array}$ \\
\hline $\begin{array}{l}\text { Ambe et al. [28] } \\
(2016)\end{array}$ & 32 & Close to $80 \%$ & Close to $80 \%$ & $51 \mu \mathrm{g} / \mathrm{g}$ & 0.86 & $\begin{array}{l}\text { 1. Study on predominantly adult population } \\
\text { 2. No significant difference in AA/controls } \\
\text { 3. Significantly more active during IE than } \\
\text { AA }\end{array}$ \\
\hline $\begin{array}{l}\text { Sarsu et al. [30] } \\
(2017)\end{array}$ & 120 & - & - & - & $\begin{array}{l}\text { UCAA: } 0.669 \\
\text { CAA: } 0.951\end{array}$ & $\begin{array}{l}\text { 1. Pediatric study } \\
\text { 2. The serum form as a more accurate tool }\end{array}$ \\
\hline $\begin{array}{l}\text { Zhou et al. [29] } \\
\text { (2019) }\end{array}$ & 84 & - & - & $106 \mu \mathrm{g} / \mathrm{g}$ & 0.928 & $\begin{array}{l}\text { 1. Study on adult population } \\
\text { 2. Relative units in commercial assays sug- } \\
\text { gested as a potential impediment for the } \\
\text { studies' design }\end{array}$ \\
\hline
\end{tabular}

$U C A A$ uncomplicated acute appendicitis, $C A A$ complicated acute appendicitis 
same patients [30]. Comparing the cases with uncomplicated $\mathrm{AA}$ and controls, the FC was determined as a less accurate biomarker in diagnosis than serum $\mathrm{CP}\left(\mathrm{AUC}_{\mathrm{FC}}=0.669\right.$ vs $\mathrm{AUC}_{\text {SERUM CP }}=0.882$ ). What is more, the comparison between patients with complicated AA and controls showed similar results $\left(\mathrm{AUC}_{\mathrm{FC}}=0.951\right.$ vs $\left.\mathrm{AUC}_{\mathrm{SERUM} \mathrm{CP}}=1.000\right)$. What is interesting is the cutoff levels of the serum CP indicated in ROC analysis have been observed on the relatively very low level as $670 \mathrm{ng} / \mathrm{ml}$ with maximal specificity. Considering current report literature, this value of serum CP may be higher in adult controls [38].

\section{Conclusion}

The level of fecal calprotectin is considered a valuable tool bringing additional data for clinicians in gastrointestinal disorders. Fecal calprotectin is a very stable form of calprotectin, which does not require a specific timing from the onset of symptoms to stool collection and further analysis. In Poland, fecal calprotectin tests are highly available due to the common use in inflammatory bowel diseases diagnosis. On the other hand, they are still relatively expensive. For now, its utility in acute appendicitis remains questionable. Unfortunately, several published studies are not consistent in their results of statistical parameters and accurate cutoff values and more reliable data are needed. However, in our opinion, it is particularly promising to focus on the fecal and serum calprotectin to develop in the future a more effective marker panel diagnosing acute appendicitis.

Author contribution Adam Makaro: drafting the work, the design of the work.

Łukasz Dziki: revising it critically for important intellectual content.

Jakub Fichna: revising it critically for important intellectual content.

Marcin Włodarczyk: the conception of the work. revising it critically for important intellectual content.

All the authors critically revised the manuscript, approved the final version to be published, and agreed to be accountable for all aspects of the work.

Funding Funding supported by the Polish National Science Center (2016/23/N/NZ5/02564 to MW).

Availability of Data and Material Not applicable.

Code Availability Not applicable.

\section{Declarations}

Conflict of Interest The authors declare no competing interests.

Ethics Approval Not applicable.
Consent to Participate Not applicable.

Consent for Publication Not applicable.

Open Access This article is licensed under a Creative Commons Attribution 4.0 International License, which permits use, sharing, adaptation, distribution and reproduction in any medium or format, as long as you give appropriate credit to the original author(s) and the source, provide a link to the Creative Commons licence, and indicate if changes were made. The images or other third party material in this article are included in the article's Creative Commons licence, unless indicated otherwise in a credit line to the material. If material is not included in the article's Creative Commons licence and your intended use is not permitted by statutory regulation or exceeds the permitted use, you will need to obtain permission directly from the copyright holder. To view a copy of this licence, visit http://creativecommons.org/licenses/by/4.0/.

\section{References}

1. F Shabani A Farasat M Mahdavi N Gheibi 2018 Calprotectin (S100A8/S100A9): a key protein between inflammation and cancer Inflamm Res 67801812 https://doi.org/10.1007/ s00011-018-1173-4

2. RM Ayling K Kok 2018 Fecal calprotectin Adv Clin Chem Elsevier Ltd 87161190 https://doi.org/10.1016/bs.acc.2018.07.005

3. Besold AN, Culbertson EM, Nam L, et al (2019) HHS public access. 10:1728-1742.https://doi.org/10.1039/c8mt00133b.Antim icrobial

4. JM Ehrchen C Sunderkötter D Foell 2009 The endogenous Tolllike receptor 4 agonist S100A8/S100A9 (calprotectin) as innate amplifier of infection, autoimmunity, and cancer J Leukoc Biol 86557566 https://doi.org/10.1189/jlb.1008647

5. S Yui Y Nakatani M Mikami 2003 Calprotectin (S100A8/ S100A9), an inflammatory protein complex from neutrophils with a broad apoptosis-inducing activity Biol Pharm Bull 26753760 https://doi.org/10.1248/bpb.26.753

6. I Stríz I Trebichavský 2004 Calprotectin - a pleiotropic molecule in acute and chronic inflammation Physiol Res 53245253

7. WPNGW Pathirana SA Paul Chubb MJ Gillett SD Vasikaran 2018 Faecal calprotectin Clin Biochem Rev 397790 https://doi.org/10. 1097/mpg.0000000000001847

8. I Bjarnason 2017 The use of fecal calprotectin in inflammatory bowel disease Gastroenterol Hepatol (N Y) 135356

9. E Burri C Beglinger 2014 The use of fecal calprotectin as a biomarker in gastrointestinal disease Expert Rev Gastroenterol Hepatol 8197210 https://doi.org/10.1586/17474124.2014.869476

10. M Sobczak A Fabisiak N Murawska 2014 Current overview of extrinsic and intrinsic factors in etiology and progression of inflammatory bowel diseases Pharmacol Reports 66766775 https://doi.org/10.1016/j.pharep.2014.04.005

11. AC Roon Von L Karamountzos S Purkayastha 2007 Diagnostic precision of fecal calprotectin for inflammatory bowel disease and colorectal malignancy Am J Gastroenterol 102803813 https:// doi.org/10.1111/j.1572-0241.2007.01126.x

12. PF Rheenen Van E Vijver Van De V Fidler 2010 Faecal calprotectin for screening of patients with suspected inflammatory bowel disease: Diagnostic meta-analysis BMJ 341188 https://doi.org/ 10.1136/bmj.c3369

13. Rokkas T, Portincasa P, Koutroubakis IE (2018) Fecal calprotectin in assessing inflammatory bowel disease endoscopic activity: a diagnostic accuracy meta-analysis. J Gastrointestin Liver Dis 27:299-306. https://doi.org/10.15403/jgld.2014.1121.273.pti 
14. A Kostas SI Siakavellas C Kosmidis 2017 Fecal calprotectin measurement is a marker of shortterm clinical outcome and presence of mucosal healing in patients with inflammatory bowel disease World J Gastroenterol 2373877396 https://doi.org/10.3748/ wjg.v23.i41.7387

15. R Mao Y Xiao X Gao 2012 Fecal calprotectin in predicting relapse of inflammatory bowel diseases: a meta-analysis of prospective studies Inflamm Bowel Dis 1818941899 https://doi.org/ 10.1002/ibd.22861

16. X Ye J Huai J Ding 2018 Diagnostic accuracy of fecal calprotectin for screening patients with colorectal cancer: a meta-analysis Turkish J Gastroenterol 29397405 https://doi.org/10.5152/tjg. 2018.17606

17. Mari A, Baker FA, Mahamid M, et al (2019) Clinical utility of fecal calprotectin: potential applications beyond inflammatory bowel disease for the primary care physician. Ann Gastroenterol 32:425-430. https://doi.org/10.20524/aog.2019.0394

18. LK Gwynn 2001 The diagnosis of acute appendicitis: clinical assessment versus computed tomography evaluation J Emerg Med 21119123 https://doi.org/10.1016/s0736-4679(01)00353-5

19. B Stewart P Khanduri C McCord 2014 Global disease burden of conditions requiring emergency surgery Br J Surg 101 e9 22 https://doi.org/10.1002/bjs.9329

20. A Bhangu K Søreide S Saverio Di 2015 Acute appendicitis: modern understanding of pathogenesis, diagnosis, and management Lancet (London, England) 38612781287 https://doi.org/10.1016/ S0140-6736(15)00275-5

21. DJ Shogilev N Duus SR Odom NI Shapiro 2014 Diagnosing appendicitis: evidence-based review of the diagnostic approach in 2014 West J Emerg Med 15859871 https://doi.org/10.5811/ westjem.2014.9.21568

22. JJ Barcia N Reissenweber 2002 Neutrophil count in the normal appendix and early appendicitis: diagnostic index of real acute inflammation Ann Diagn Pathol 6352356 https://doi.org/10. 1053/adpa.2002.36659

23. JF Bealer M Colgin 2010 S100A8/A9: a potential new diagnostic aid for acute appendicitis Acad Emerg Med 17333336 https:// doi.org/10.1111/j.1553-2712.2010.00663.x

24. AM Mills DS Huckins H Kwok 2012 Diagnostic characteristics of S100A8/A9 in a multicenter study of patients with acute right lower quadrant abdominal pain Acad Emerg Med 194855 https:// doi.org/10.1111/j.1553-2712.2011.01259.x

25. G Thuijls JPM Derikx FJ Prakken 2011 A pilot study on potential new plasma markers for diagnosis of acute appendicitis Am J Emerg Med 29256260 https://doi.org/10.1016/j.ajem.2009.09. 029

26. M Cikot KD Peker MA Bozkurt 2016 Plasma calprotectin level: usage in distinction of uncomplicated from complicated acute appendicitis World J Emerg Surg 11712 https://doi.org/10.1186/ s13017-016-0062-9

27. PC Ambe D Gödde L Bönicke 2016 Calprotectin could be a potential biomarker for acute appendicitis J Transl Med 14107 https://doi.org/10.1186/s12967-016-0863-3
28. PC Ambe V Orth D Gödde H Zirngibl 2016 Improving the preoperative diagnostic accuracy of acute appendicitis. Can Fecal Calprotectin Be Helpful? PLoS One 11 e0168769 https://doi.org/ 10.1371/journal.pone.0168769

29. W Zhou H Qiao W Yuan 2019 Diagnostic utility of fecal calprotectin in patients presenting to the emergency department with suspected acute appendicitis Am J Emerg Med https://doi.org/10. 1016/j.ajem.2019.10.022

30. SB Sarsu AB Erbagci H Ulusal 2017 The Place of calprotectin, lactoferrin, and high-mobility Group Box 1 protein on diagnosis of acute appendicitis with children Indian J Surg 79131136 https://doi.org/10.1007/s12262-015-1441-2

31. M Frountzas K Stergios D Kopsini 2018 Alvarado or RIPASA score for diagnosis of acute appendicitis? A meta-analysis of randomized trials Int J Surg 56307314 https://doi.org/10.1016/j.ijsu. 2018.07.003

32. DS Huckins HK Simon K Copeland 2013 A novel biomarker panel to rule out acute appendicitis in pediatric patients with abdominal pain Am J Emerg Med 3113681375 https://doi.org/ 10.1016/j.ajem.2013.06.016

33. J González Del Castillo FJ Ayuso V Trenchs 2016 Diagnostic accuracy of the APPY 1 test in patients aged 2-20 years with suspected acute appendicitis presenting to emergency departments Emerg Med J 33853859 https://doi.org/10.1136/emerm ed-2015-205259

34. J Benito Y Acedo L Medrano 2016 Usefulness of new and traditional serum biomarkers in children with suspected appendicitis Am J Emerg Med 34871876 https://doi.org/10.1016/j.ajem.2016. 02.011

35. H Depinet K Copeland J Gogain 2016 Addition of a biomarker panel to a clinical score to identify patients at low risk for appendicitis Am J Emerg Med 3422662271 https://doi.org/10.1016/j. ajem.2016.08.018

36. Akgül F, Er A, Ulusoy E, et al (2019) Integration of physical examination, old and new biomarkers, and ultrasonography by using neural networks for pediatric appendicitis. Pediatr Emerg Care Publish Ah:1-7. https://doi.org/10.1097/pec.0000000000 001904

37. J Benito S Fernandez M Gendive 2019 American Journal of Emergency Medicine A new clinical score to identify children at low risk for appendicitis th Am J Emerg Med https://doi.org/10. 1016/j.ajem.2019.05.050

38. M-A Meuwis G Vernier-Massouille JC Grimaud 2013 Serum calprotectin as a biomarker for Crohn's disease J Crohns Colitis 7 e678 e683 https://doi.org/10.1016/j.crohns.2013.06.008

Publisher's Note Springer Nature remains neutral with regard to jurisdictional claims in published maps and institutional affiliations. 